\title{
IN DEFENCE OF THE BELIEF-PLUS MODEL OF FAITH
}

\author{
JOSHUA MUGG \\ Indiana University Kokomo
}

\begin{abstract}
I defend the claim that propositional religious faith that $\mathrm{p}$ implies belief that $\mathrm{p}$. While this claim might seem trivial, it has been criticized by Alston, Pojman, Audi, and (more recently) McKaughan and Howard-Snyder. I begin by defending this view (call it the belief-plus model of faith) against four objections. In addition to criticizing the belief-plus model, each of the above philosophers have offered their own alternatives to the belief-plus model. I focus on McKaughan's (2013) recent accounts of faith: 'trusting acceptance' and 'hopeful affirmation'. I argue, following Howard-Snyder, that hopeful affirmation fails to give sufficient conditions for faith. I then argue that there is no reason to think that the token acceptances in faith as trusting acceptance are not instances of belief.
\end{abstract}

\section{INTRODUCTION}

Religious faith that God exists requires belief that God exists. Although this claim might seem trivial, McKaughan (2013), along with a number of others, has argued that this view (call it the 'belief-plus model') is false. McKaughan goes on to claim that faith might be 'trusting acceptance' or 'hopeful affirmation', neither of which requires belief. I defend the beliefplus model of propositional religious faith. I limit myself to propositional religious faith because I am unsure whether faith in non-religious contexts (i.e. that the Cleveland Browns will win the Super Bowl) is of the same kind as faith that (e.g.) God exists, and I am unsure whether 'belief in' denotes a kind in the way that 'belief that' does. I begin by replying to four objections to the belief-plus model of faith. I then argue that McKaughan's 'hopeful affirmation' account of faith fails to give sufficient conditions for faith. Finally, I argue that McKaughan's 'trusting acceptance' account of faith tacitly involves a weak kind of belief. 


\section{OBJECTIONS TO THE BELIEF-PLUS MODEL}

In this section, I survey and reply to some common objections to the belief-plus model of propositional religious faith. First, McKaughan (along with Pojman 1986, Audi 1991, and Howard-Snyder 2013) all claim that while one can have faith that $\mathrm{p}$ while holding doubts that $\mathrm{p}$, 'belief that $\mathrm{p}$ is at odds with being in doubt about it, not least because, if one is in doubt, one will lack tendencies that one has if one believes' (Howard-Snyder 2013: 361). Citing Luther, Calvin, and Plantinga, McKaughan claims that on the belief-plus model 'the intellectual content of faith, or part of it, is sometimes alleged to require and even to enjoy certification by high epistemic credentials. It has the status of knowledge [...] warranted by demonstration, direct perception, or the alleged infusion of grace' (McKaughan 2013: 106). Thus, on the beliefplus model, faith precludes significant doubt. However, many devout Christians have experienced doubt. McKaughan offers Mother Teresa as a paradigmatic example. Thus, faith is compatible with doubt 'in a way or to an extent that belief is not' (McKaughan 2013: 107). Call this the objection from doubt.

The objection from doubt saddles the belief-plus model with an account of belief according to which belief requires high credence. As it happens, a number of belief-plus theorists endorse this high credence for belief, especially for those beliefs that are partly constitutive of faith. It is true that Plantinga, Luther, and Calvin's conception of faith cannot accommodate serious religious doubt, but these theorists already think that serious doubt and faith are incompatible. These theorists will happily say that Mother Teresa experienced a lapse of faith when she doubted. Thus, the objection from doubt begs the question against them.

While some philosophers and theologians do want to preclude doubt from faith, I am sympathetic to the view that faith is compatible with at least some doubt. Notice that there is nothing in the belief-plus model itself that requires that faith that $\mathrm{p}$ implies knowledge that $\mathrm{p}$ (or certainty that $\mathrm{p}$, or some high epistemic status that $\mathrm{p}$ ). I can believe that my car is where I parked it while recognizing that it might have been stolen - thus entertaining doubts that it is where I parked it. Likewise, I can believe that God exists while entertaining doubts about God's existence. It is true that if I entertain doubts about a proposition, then I will be less likely to manifest some of the dispositions that Howard-Snyder (drawing from Alston) says are constitutive of belief. However, that I would be less likely 
to manifest these dispositions, does not imply that I lack the belief, since these are mere tendencies.

Anticipating my objection, McKaughan says that 'there do seem to be some clear lower bounds' than certainty for belief, and those bounds will 'depend on what one takes belief to be' (2013: 107). While I agree that whether this objection succeeds or not depends on the nature of belief, the objector to the belief-plus model must frame the objection from doubt with some specific boundary to belief in mind, and there are conceptions of belief that can accommodate a good deal of doubt. McKaughan might reply that while faith and belief both allow for some degree of doubt, faith allows for a greater degree of doubt than belief. However, it is unclear why the belief-plus model advocate must accept this claim. In short, the objection from doubt either attacks a strawman in saddling the belief-plus model with a very high boundary for belief as a necessary condition for faith, or is question-begging against those who outright claim faith requires knowledge or certainty.

In a second objection, McKaughan, following Smith (1998a, 1998b), argues that the meaning of 'belief' has changed in the modern era. Today, belief 'refers to a state of mind [or] a disposition to assent to a set of propositions' (McKaughan 2013: 108). However, in Septuagint, Greek

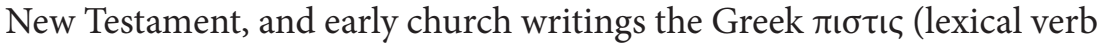
form $\pi\lrcorner \sigma \tau \varepsilon \cup \omega)$ and the Latin credo have a rather different meaning. McKaughan claims that $\pi$ $\sigma \tau \varepsilon v \omega$ should almost always be translated as 'trust' or 'have faith. 'Credo' is a compound of 'cor' or 'cordis' ('heart') and 'do' or 'dere' ('to put'). Hence 'credo' translates literally as 'I set my heart'. Smith argues that there is an affective component to the meaning of credo. McKaughan concludes that belief (as we understand it today) has little to do with faith. He calls this the problem of meaning drift.

As a preliminary note, it is important to recognize that belief comes to philosophy from our folk psychology, unlike (e.g.) validity or quantification: we should be cautious when moving from religious uses of the term to philosophical uses of the term. Here McKaughan and I are in agreement. We must exercise caution to avoid talking past one another.

In fact, a study of the Greek New Testament and Septuagint can only strengthen the case that belief is a component of faith. First, note that Greek has only one word ( $\pi \iota \sigma \tau \iota \varsigma$ or $\pi\llcorner\sigma \tau \varepsilon v \omega$ ) for faith and belief whereas English has two. If word studies are supposed to illuminate the nature of faith and belief (as McKaughan assumes they do), this single Greek word 
suggests that faith and belief are closely related. Some philosophers, such as Cohen, Alston, and Howard-Snyder, claim that belief that $\mathrm{p}$ implies a disposition to feel that $\mathrm{p}$ is true. Concerning our modern usage of 'belief', there are beliefs that are affective. For example, consider implicit beliefs. These beliefs are affective and sometimes at odds with what one would explicitly affirm. Perhaps McKaughan might claim that such implicit attitudes are not beliefs. I cannot offer a full analysis here, but if philosophers reject such implicit states from our concept of 'belief', then epistemologists study something distinct from the mental state that non-philosophers have in mind when speaking of belief that God exists. Such a dialectical move threatens to tear the metaphysics of belief from its common sense moorings. Our philosophical approach should be to study the mental state to which the term 'belief' refers; ${ }^{1}$ we want to study belief, rather than 'belief-in-the-mouth-of-the-folk' or 'belief-in-the-mouth-of-the-philosopher'.

Although McKaughan only levels the above two objections, he might avail himself of two further objections to the belief-plus model of faith, which Howard-Snyder (2013) offers. Following Alston (1996), Howard-Snyder claims that if one believes that $\mathrm{p}$, then one will tend to be surprised if it turns out that not-p. However, one can have faith that $\mathrm{p}$ while lacking a tendency to be surprised if it turns out that not-p. Thus, one can have faith without belief.

Importantly, it is not a problem for the belief-plus model that there are cases in which a subject has faith that $p$, but upon learning that $p$ is false, is not surprised. This is because, according to Alston and HowardSnyder, surprise upon learning that not-p is not a necessary condition on belief that $\mathrm{p}$. Rather, belief that $\mathrm{p}$ implies that the subject will tend to be surprised upon learning that not-p. I might not be surprised to learn that I have only four, rather than five, subway tokens in my pocket (as I currently believe), since the tokens are small and easily lost. HowardSnyder agrees to all of this. Thus, we should understand his argument as follows:

(1) For all cases where a subject believes that $p$, that subject is disposed to be surprised upon learning that not-p.

(2) There are cases where a subject has faith that $\mathrm{p}$, but is not disposed to be surprised upon learning that not-p.

${ }^{1}$ I am assuming an externalist account of reference. 
Conclusion: Therefore, there are cases where a subject has faith that $\mathrm{p}$, but does not believe that $\mathrm{p}$.

Howard-Snyder's support for the second premise in this argument is utterly lacking. Let's suppose an account of dispositions according to which a disposition is a property that mediates between a stimulus and a manifestation (Bird 1998, Mumford 1998, Martin 2007, Heil 2003). A number of philosophers working on the nature of dispositions ground modality in dispositional properties (Heil 2003, Jacobs 2010, Martin 2007, Martin \& Heil 1998, Pruss 2002). To put it a bit more precisely, it is possible that an object $\mathrm{X}$ if and only if that object possesses (or possessed) a disposition, the manifestation of which includes either 1) that object's possessing $\mathrm{X}$ or 2) a further disposition the manifestation of which includes that object's possessing X. Now, for any subject who has faith that $\mathrm{p}$, it is possible that the subject who has faith that $\mathrm{p}$ will be surprised upon learning that not-p. Thus, on a dispositional account of modality, any subject who has faith that $\mathrm{p}$ either 1) possesses a disposition for surprise that not-p or 2) possesses a disposition for a disposition for surprise that not-p.

Now, one might object that this reply requires the subject to be disposed to be surprised, but also be disposed not to be surprised, but it makes no sense to say that a subject possesses dispositions of contradictory manifestations. I see no reason to think that subjects cannot possess dispositions for contradictory manifestations. Consider a car stopped on a hill. It is simultaneously disposed to roll down and move up. Which disposition manifests depends upon which stimulus conditions obtain: if the driver releases the brake while stepping on the gas, it will go up the hill, but if the driver releases the brake while failing to step on the gas, the car will roll down the hill. Furthermore, defenders of dispositional accounts of modality will happily agree that objects possess dispositions for incompatible manifestations, since modal claims are supposed to be grounded in dispositions.

Perhaps the chief rival of the above account of dispositions is a conditional analysis of dispositions (Lewis 1973, 1997), according to which dispositions are reducible to counterfactual conditionals, which are in turn analysed by relations between possible worlds. On this account, an object is disposed to $\mathrm{X}$ just in case if the stimulus conditions were to obtain, then $\mathrm{X} .{ }^{2}$ Conditional analysis likely renders premise 2 true, since there will be cases where a subject has faith that $\mathrm{p}$, but the subject 
is not surprised in the closest possible world where she learns that not-p. However, conditional analysis makes the surprise condition on belief too strong. I believe I have five (small) subway tokens in my pocket, but if I were to learn that I have only four, I am not surprised, since I lose them all the time. Thus, on conditional analysis, I lack the disposition to be surprised. The problem is that, on a conditional analysis of dispositions, we cannot draw a distinction between being surprised if it turns out that not-p as a necessary condition on belief that $\mathrm{p}$, and being disposed to be surprised if it turns out that not-p being a necessary condition on belief that $\mathrm{p}$. This should not be surprising, since dispositions are reduced to counterfactual conditionals on conditional analysis.

Thus, on the two dominant accounts of dispositions, Howard-Snyder's objection fails. On those accounts of dispositions that do not attempt to reduce dispositions to counterfactuals, premise 2 is false. On the other hand, while a conditional analysis of dispositions renders premise 2 true, it does so at the cost of making surprise upon learning that not-p into a necessary condition of believing that $\mathrm{p}$.

In his final objection, Howard-Snyder asserts that one can have faith that $\mathrm{p}$ while believing that $\mathrm{p}$ is only likely and not believing that $\mathrm{p}$. For example, a cancer patient might have faith that he will pull through, giving him courage 'even if he only believes that he will probably succeed' (Howard-Snyder 2013: 361). This final objection is question-begging, since Howard-Snyder asserts that the cancer patient lacks the belief that he will live, but has faith that he will live. What would be required for this objection to succeed is an independent reason for thinking that this patient lacks the putative belief. Indeed, I suspect even McKaughan would claim that Howard-Snyder goes too far, since he indicates that to have faith that $\mathrm{p}$, one must not believe that not-p (McKaughan 2013: 116).

I conclude that these objections to the belief-plus model of faith fail. Since McKaughan sees the inadequacy of the belief-plus model as a reason for the need of novel accounts of faith, I have undercut the motivation for his novel accounts of faith. However, the opponent of the belief-plus model might point out that there exist sufficient accounts of

${ }^{2}$ Things are more complicated, since dispositions can be finkish (the stimulus conditions are identical to conditions for loss of the disposition). Opponents of the conditional analysis of dispositions have argued from the existence of finkish dispositions to the falsity of the conditional analysis of dispositions. I suspect that the only way out for the defender of conditional analysis is to deny the existence of finkish dispositions, thereby allowing the above counterfactual to remain true (see McKitrick, 2003). 
faith that do not involve belief. As such, the defender of the belief-plus model must either show that these novel accounts either fail to give sufficient conditions for faith, or do (tacitly) involve belief. In the next section, I argue that McKaughan's accounts fail in one of these two ways.

\section{ONE OR TWO NEW ACCOUNTS OF FAITH}

McKaughan offers two alternatives to the belief-plus model of faith. First, faith might be 'trusting acceptance'. Roughly, to accept $\mathrm{p}$ is to adopt a policy of acting as though $\mathrm{p}$ were the case. Alston points out that there are two senses of acceptance. There is an action (deciding to treat $\mathrm{p}$ as true) and a resulting mental state from that action (premising $\mathrm{p}$ as true). When speaking of propositional faith as trusting acceptance, we should think of acceptance in the second sense, which characterizes faith as an enduring mental state rather than a one-time action. ${ }^{3}$ A number of philosophers have claimed that acceptance and belief are distinct kinds of mental states (see Alston 1996, 2007; Cohen 1992; Frankish 2004; Stalnaker 1984). McKaughan draws most heavily from Alston and Cohen's accounts, and his trusting acceptance account of faith is remarkably similar to Alston's (1996) account of faith. According to Alston 'to accept [the central doctrines of the Christian faith] is to perform a voluntary act of committing oneself to them, to resolve to use them as a basis for one's thought, attitude, and behaviour. (And, of course, it involves being disposed to do so as a result of this voluntary acceptance)' (Alston 1996: 17). McKaughan uses Swinburne's (2005) account of trust, according to which, 'to trust someone is to act on the assumption that she will do for you what she knows that you want or need, when the evidence gives some reason for supposing that she may not and where there will be bad consequences if the assumption is false' (Swinburne 2005: 144). McKaughan, following Alston (1996), emphasizes the personal nature of trust: 'trust and the associated concepts of trustworthiness or faithfulness, in their primary usages, involve personal relations' (McKaughan 2013: 109). Thus, on the trusting acceptance account of faith, faith that God exists is acting (and possessing the relevant mental state as a result) as though there is a person (God) upon whom one can rely. ${ }^{4}$

\footnotetext{
${ }^{3}$ In what follows, 'acceptance' refers to the mental state unless otherwise indicated.

${ }^{4}$ Similarly, Howard-Snyder claims that acceptance 'can stand in for the positive cognitive stance faith requires' instead of belief (2013: 362), though even accepting God's existence is not necessary for having faith, since one might merely assume that God exists
} 
McKaughan offers a second account of faith, according to which faith is 'hopeful affirmation'. McKaughan explains, 'for any subject $S$ and proposition $p$, to say that $S$ hopes that $p$ involves at least that (1) $S$ desires that $\mathrm{p}$ and (2) S does not believe that $\mathrm{p}$ is impossible' (McKaughan 2013: 112). While one does not always act as though the object of one's hope is true, McKaughan claims that hope can be action-guiding. For example, a castaway might (wisely) build a fire hoping to signal a passing ship or plane, even if there is no evidence that a plane or ship is nearby (see Jordan 2006: 1). However, even if S hopes that she will win the lottery, S does not act as though she will win the lottery (McKaughan 2013: 4).

Howard-Snyder says that hopeful affirmation is merely a necessary condition on faith (2013: 362-363), ${ }^{5}$ and even McKaughan admits this might be so. I cannot claim to have faith that $\mathrm{p}$ if faith that $\mathrm{p}$ does not affect my behaviour. That is, faith is action-guiding. On this point McKaughan and I agree (see McKaughan 2013: 114). Now consider McKaughan's example of non-action-guiding hope: $S$ desires that she will win the lottery, and $S$ believes it is possible. In this case, $S$ does not have faith that she will win the lottery. However, $S$ hopefully affirms she will win. Therefore, hopeful affirmation is not sufficient for faith.

McKaughan anticipates the objection that hopeful affirmation is not action-guiding on its own. In response, he suggests that if $S$ did desire that $\mathrm{p}$ and believed that $\mathrm{p}$ was possible, ${ }^{6}$ then there would be a difference in action, as in the castaway building a fire. McKaughan seems to add in a condition to his account: faith is 'action-guiding hopeful affirmation'. However, such actions on the part of the castaway constitute acceptance that there is a ship or plane nearby.

It should not be surprising that hope alone is not action-guiding, since desire alone is not action-guiding. Desire must be coupled with some belief-like state: my desire for beer combined with my belief that there is beer in the fridge causes me to open the fridge. Since faith is

(and assuming, Howard-Snyder claims, is distinct from belief and acceptance) (2013: 365-366). My argument against McKaughan's trusting-acceptance account in the next section can be equally levelled against Howard-Snyder's account of faith.

${ }^{5}$ Howard-Snyder claims that faith that $\mathrm{p}$ requires a positive evaluation of $\mathrm{p}$, a positive conative orientation toward $\mathrm{p}$, and a positive cognitive stance toward $\mathrm{p}$. Hopeful affirmation fails to fulfil the last of these criteria, and as such, is not sufficient for being faith.

${ }^{6}$ Note that 'believed that $\mathrm{p}$ is possible' is stronger than what McKaughan claims is necessary for hope, namely, 'not believing that p is impossible'. 
action-guiding, it must have some kind of belief-like state as a part of it. Thus, faith as 'action-guiding hopeful affirmation' falls back on using acceptance or some other belief-like state.

\section{ACCEPTANCE, FAITH, AND BELIEF}

Once a new mental kind, such as acceptance, is added to our ontology, it is natural to apply it elsewhere. However, it is important not to alter the concept when applying it, lest the argument for its distinctness be undercut. Thus, it will be helpful here to consider cases in which it is plausible to think that subjects accept a proposition without believing it. There are cases in which it is clear that subjects do not believe a proposition, but they do use that proposition in some way. For example, a lawyer who knows her client is guilty will accept that her client is innocent in the context of the courtroom. Similarly, an endurantist who believes that perdurantism is incoherent is able to engage in a conversation about how perdurantism fits with various views on the constitution relation. As the endurantist enters into a discussion of what would follow if perdurantism were true, what should we say of her stance toward the truth of perdurantism? Clearly she does not believe it to be true. Rather she is merely 'premising' the proposition that perdurantism is true. We may call this premising 'acceptance'. Acceptance of this sort is a very weak doxastic state. We might think of it as mere premising. ${ }^{7}$ Clearly these instances of acceptance are not instances of belief, which is why acceptance should be added to our mental ontology. Arguably, acceptance has four properties that distinguish it from belief: 1) it can be formed in a direct basic way (i.e. in the same way that I can raise my hand (see Alston 1988: 263), 2) it is only held in a narrow domain, 3) it is responsive to pragmatic, but not evidential, considerations, and 4) subjects may lack a feeling of rightness when considering the proposition in question.

Presumably acceptance and belief are not mutually exclusive. One might believe a proposition is true while accepting that proposition as true. Since none of the above conditions are necessary conditions on acceptance, this is a possibility. As such, that faith might be trusting acceptance does not imply that faith need not involve belief, since all the instances of acceptance in faith might be instances of belief. McKaughan

${ }^{7}$ Premising is similar to what Howard-Snyder calls 'entertaining'. 
and Alston could reply by arguing that the acceptance involved in faith bears at least one property that belief lacks. Presumably McKaughan does not argue this way because he believes he has already established that faith does not always include belief, given his two objections to the belief-plus model. Alston (1996), on the other hand, seems to argue against the belief-plus model in exactly this way. He especially argues that one might have faith that God exists while lacking a feeling of rightness that God exists, and that one can voluntarily have faith that God exists, but cannot voluntarily form the belief that God exists.

In the remainder of this section, I will argue that the four properties outlined above fail to do the work that McKaughan and Alston need them to do. First, I argue that beliefs may lack a feeling of rightness. Thus, a subject's lacking a feeling of rightness that $\mathrm{p}$ does not imply that the subject does not believe that $\mathrm{p}$. I then argue that the acceptance involved in genuine cases of faith fails to bear the properties that distinguish belief from acceptance.

\subsection{Feeling of Rightness}

Cohen claims that a subject believes that $\mathrm{p}$ if and only if she is disposed to feel that $\mathrm{p}$ when that subject considers $\mathrm{p}$ (Cohen 1992: 5). Acceptance, on the other hand, is to 'adopt a policy of deeming, positing, or postulating that $\mathrm{p}$ - i.e. of including that proposition or rule among one's premises for deciding what to do or think in a particular context, whether or not one feels it to be true that p' (Cohen 1992: 4). I take 'feeling that $\mathrm{p}$ is true' to be a metacognitive attitude which some have called a 'feeling of rightness' (or FOR) (see Thompson 2009, Stanovich, 2011). Others, such as Alston and Howard-Snyder, also take the disposition for a FOR as a necessary condition for belief, and use this condition as a way to distinguish belief from acceptance (Alston 1996: 3-4).

A disposition for a FOR is not a necessary condition on belief. It is possible for a subject to harbour implicitly racist attitudes while explicitly disavowing them (see Dovidio, Gaertner, \& Kawakami 2011). Many philosophers claim that these implicit attitudes are implicit beliefs (sometimes called 'aversive beliefs' because subjects are averse to their own attitudes). If these implicit attitudes are beliefs, and subjects are averse to them, then there are implicit beliefs for which subjects do not possess a FOR, since if those subjects were to consider the matter they would not feel as if the racist proposition is true. 
Now, Alston and others might object that such implicit racists do have a FOR when considering racist propositions, but the implicit racists are unwilling to admit to possessing this FOR. While some individuals might deny their FOR for racist propositions, surely at least some individuals do not have a FOR for racist propositions, but implicitly believe racist propositions. It is for this reason that many subjects are surprised when their Implicit Association Test tells them that they strongly prefer white faces to black faces.

Even some explicit beliefs lack a FOR. Suppose I read an argument for the Copenhagen interpretation of quantum mechanics and I find the argument sound. As a consequence, I formulate the belief that Schrödinger's cat is both alive and dead. I have no FOR here. Indeed, for some, the counterintuitive nature of the theory is part of the appeal. Furthermore, when I come to believe a philosophical position, I often lack a FOR for that proposition (though the feeling might come over time). Further examples are provided by the heuristics and biases literature, where a FOR remains for a normatively incorrect response even after a subject comes to believe the correct response. In the famous Linda the bank-teller case, subjects are given a description of Linda that 'fits well' with her being a feminist, but not being a bank-teller (Tversky \& Kahneman 1983). They are then asked which is more likely: A) Linda is a bank-teller, or B) Linda is a bank-teller and active in the feminist movement. Even after subjects understand that $\mathrm{A}$ is at least as likely as $\mathrm{B}$, the FOR remains that $\mathrm{B}$ is more likely than $\mathrm{A}$. That $\mathrm{A}$ is more likely than B does not feel correct, even though we know it is. Sloman claims that he 'can trace through the probability argument and concede its validity, while sensing that a state of affairs that [he] can imagine much more easily has a greater chance of obtaining' (1996: 12). ${ }^{8}$ Thus, Cohen and Alston's requirement for belief is too stringent. Distinguishing acceptance and belief using FOR will not do.

One might suggest that Alston could weaken his claim by saying that a disposition for a FOR is typical, but not necessary, for belief. Suppose we grant Alston this claim. Would the resulting criterion be problematic for the belief-plus model? I think not. Consider the following argument:

(1) Typically, if $S$ believes that $p$, then $S$ is disposed for a FOR when considering $\mathrm{p}$.

${ }^{8}$ Sloman (1996) takes this to support the two-system hypothesis. However, see Keren and Schul (2009) and Mugg (2013). 
(2) If $S$ has faith that $p$, then $S$ believes that $p$.

Conclusion: Therefore, typically, if $S$ has faith that $\mathrm{p}$, then $\mathrm{S}$ is disposed for a FOR when considering $\mathrm{p}$.

There are two problems. First, this argument is invalid. The set of beliefs present in faith might be a subset of the set of beliefs lacking a disposition for a FOR. Second, it is not clear that the conclusion of this argument is problematic for the belief-plus model. While some religious people might lack a FOR when considering the central doctrines of their faith, it is not clear that this is typical. It seems plausible that many subjects do possess a FOR for the doctrines of their faith. I conclude that FOR is not a necessary condition on belief, and if FOR merely tends to correlate with belief, then it is no problem to the belief-plus model.

\subsection{Pragmatic Reasoning}

McKaughan argues that faith as trusting acceptance is responsive to pragmatic considerations. For this to be a problem for the belief-plus model, it would also need to be the case that faith is not responsive to evidence. However, it seems that faith is responsive to evidence. McKaughan admits that it is not possible to have faith that $\mathrm{p}$ while believing that not-p. According to McKaughan, one must, at the very least, be agnostic about $\mathrm{p}$. However, a subject can accept that $\mathrm{p}$ while believing (or even knowing) that not-p. Again, a lawyer might accept her client's innocence, even though she knows them to be guilty. No evidence to the contrary will alter her acceptance; her acceptance is purely pragmatic. Evidence need not affect acceptance whatsoever, but it does affect faith to at least some degree. Thus, faith is responsive to evidential considerations in a way that acceptance is not. Therefore, that acceptance may be recalcitrant to evidence, while belief is not, is of no help to the opponent of the belief-plus model.

\subsection{Context}

For convenience, let's call acceptance that is bracketed to a small domain 'thin acceptance', and acceptance that is pervasive 'thick acceptance.' Instances of thin acceptance are not instances of belief, since beliefs are

${ }^{9}$ This distinction need not mark out cognitive kinds, and the distinction between the two likely admits border cases. 
not bracketed to one domain. If a lawyer treats her client as innocent only in a legal context, this is grounds to say that she merely accepts that her client is innocent. Importantly, token thick acceptances are not necessarily belief tokens, since the token acceptance might lack necessary conditions of belief (i.e. the token acceptance might be directly and basically formed, or be responsive to pragmatic considerations but not evidential considerations).

Notice that the positive attitude in instances of religious faith is significantly stronger than thin acceptance. Alston (1996), in arguing that acceptance-faith need not be inferior to belief-faith, claims that the acceptance in faith cannot be 'thin'.

The person who accepts the doctrines is not necessarily inferior to the believer in commitment to the Christian life, or in the seriousness, faithfulness, or intensity with which she pursues it. The accepter may pray just as faithfully, worship God just as regularly, strive as earnestly to follow the way of life enjoined on us by Christ, look as pervasively on interpersonal relationships, vocation, and social issues through the lens of the Christian faith. (Alston 1996: 17, emphasis mine)

Consider the faith of Mother Teresa. Her acceptance that God exists was action-guiding in all domains of her life, even though, as McKaughan points out, she frequently had doubts about the existence of God. On McKaughan's analysis, Mother Teresa merely accepted God's existence, rather than believing that God exists. ${ }^{10}$ So Mother Teresa 'thickly accepted' that God exists. We cannot use thin acceptance as the doxastic state in religious faith because religious faith is not supposed to be bracketed to one domain. The nominal Christian who thinly accepts God's existence (e.g., only within the context of Sunday morning) does not have faith. Thin acceptance is contextual - but, in the case of faith, the context of the positive doxastic attitude regarding God's existence will be very large, perhaps encompassing all the domains of one's life. Thus, for acceptance to serve as a doxastic state in faith, it must be thick acceptance. I conclude that the contextual nature of acceptance does not imply that the acceptance in faith is not belief.

${ }_{10}$ While McKaughan does not explicitly claim that Mother Teresa did not believe that God exists, it is implicit in his argument from doubt (see section 2). If McKaughan admits that Mother Teresa did believe that God exists, then her faith provides no counterexample to the belief-plus model. 


\subsection{Basic direct formation}

Finally, I turn to the claim that acceptance can be formed in a basic and direct way (i.e. in the same way that I can lift my arm), while belief cannot. While I may accept a proposition as true at one time, I may come to believe that proposition at a later time as a result of accepting that proposition. My attitude toward that proposition has changed from merely treating it as true to treating it as true and taking it as true. I no longer merely accept the proposition; I believe it, and the fact that my initial positive cognitive stance toward that proposition was formed in a basic direct way does not imply that I do not believe it. Indeed, Alston himself says that acceptance may turn into belief 'as one gets deeper and deeper into the religion one has accepted' (1996: 18). However, then the defender of the belief-plus model can simply claim that acceptance without belief is a means to faith rather than partly constitutive of faith.

McKaughan could reply that at the moment that a subject comes to accept and trust that God exists, the subject has faith that God exists. However, at that moment, the subject does not yet believe that God exists. Thus, on the trusting acceptance account of faith, faith that God exists does not imply belief that God exists. However, it is unclear why the defender of the belief-plus model should agree that the subject possesses faith at the moment that they first accept and trust that God exists. The belief-plus advocate may say that the subject has formed a mental state (acceptance) that may lead to belief and faith, but at the moment, she still lacks faith. Thus, it would seem that the belief-plus model is compatible with non-voluntarism about belief. However, things are not so simple, since Alston has an argument for the claim that faith can be formed voluntarily.

Alston asks us to suppose that faith requires 'certain propositional beliefs, and these [beliefs] are not within our voluntary control, how can anyone require us to have faith, and how can any merit attach to our doing so?' (1996: 25). It would be odd to claim that you ought to have faith that God exists, but also hold that you have no control over part of what constitutes that faith. Alston does not claim that his argument is decisive, and points out that defenders of the belief-plus model do have nuanced solutions to it. However, he claims that a simpler explanation is available: faith only requires acceptance.

Alston argues that we do not have direct control over any of our beliefs. In Alston's taxonomy, direct control comes in two forms: basic 
and non-basic (1996: 269). If a subject has basic direct control over a belief, she would be able to believe a specific proposition 'at will', in the same way that I can raise my hand 'at will'. In contrast, if a subject has non-basic direct control over a belief, she would be able to believe a specific proposition 'while uninterruptedly guided by the intention to do so' (Alston 1996: 277). I have non-basic direct control over turning on a light.

Alston contrasts direct control with 'long range control'. Long range control is 'the capacity to bring about a state of affairs, C, by doing something (usually a number of different things) repeatedly over a considerable period of time, interrupted by activity directed to other goals' (Alston 1996: 275). Alston agrees that we do have some long range control over our belief. He writes: 'devices employed include selective exposure to evidence, selective attention to supporting considerations, seeking the company of believers and avoiding non-believers, selfsuggestion, and (possibly) more bizarre methods like hypnotism' (Alston 1996: 275), but such cases are few. I take the claim about control regarding the belief/acceptance distinction to be about direct control only.

I agree with Alston that belief is not under our control in a direct and basic way. However, belief need not be under our direct and basic control in order for it to be meritorious for someone to hold certain beliefs. We hold subjects responsible for racist beliefs, beliefs that climate change is not happening, and that the world is flat. Perhaps only indirect control is needed to hold subjects responsible for such beliefs - just as we can reasonably hold subjects responsible for their cholesterol levels, even though subjects do not have direct control over their cholesterol levels. To be sure, Alston claims that we do not have long range control over our beliefs, since subjects are probably not very likely to succeed in generating the desired belief (Alston 1988: 276).

I will argue that humans have non-basic direct control over some beliefs, which is sufficient for treating certain beliefs as meritorious. Alston is very clear on the conditions for the existence of non-basic direct control over belief: non-basic direct control of belief requires, 'that the search for evidence was undertaken with the intention of taking up a certain particular attitude toward a particular proposition' (Alston 1988: 271). I will argue that a subject's forming a specific belief can be uninterruptedly guided by an intention to form that specific belief. In situations in which it is not clear whether $\mathrm{p}$ or not-p, a subject may choose what kind of evidence she gathers. Suppose a subject hears that 
there was a violent police intervention at an anti-war rally, and does not know whether this was a peaceful rally or not. Depending upon whether she wants to form the belief that 'the police were in the wrong' or 'the protestors were in the wrong', she can choose which news source to read. She can choose to read the Fox News webpage or Counterpunch. As Sartre (1946) points out, although we do not choose what advice we receive from our friends, we can choose which friend we ask for advice, knowing what kind of advice they will give. Since the belief would be acquired through an uninterrupted intention to form it, it would be directly formed.

Alston objects to these kinds of cases because all that the subject has control over is putting herself in a position to believe some proposition, rather than a particular proposition. As a subject investigates, sometimes she will find evidence for $p$, and other times for not-p. In the above example, even if the subject chooses a news source with a predictable bias, she does not control what that news source will say on a particular occasion. Although biased news sources will be more or less sympathetic to the protesters, there will be cases where even the most biased news source will admit to wrongdoing (on the part of the protesters or the police).

All this objection shows is that we do not always achieve what we intend. A subject might intend to form the belief that the protesters were at fault, but fail to do so, but this is no problem for the voluntarist. I might intend to turn on the light, but fail to do so. Perhaps I switch the fan instead of the light switch, or perhaps the connection from the switch to the light has been severed, but this is not a counterexample to the claim that I can voluntarily turn on a light.

One might further object to these cases by arguing that the subject only has indirect control over which specific proposition they come to believe. While I have direct control over what I eat, I only have indirect control over my cholesterol levels. Perhaps, but even indirect control seems sufficient to think that certain beliefs are meritorious, thereby undercutting Alston's argument.

\subsection{Putting it all together}

My aim in this section was to undercut an argument - based on the claim that trusting acceptance is sufficient for faith - that the belief-plus model is false. I argued that subjects may lack a FOR for p even if they 
believe that $\mathrm{p}$. As such, it is not a problem for the belief-plus model that one might have faith that God exists without possessing a FOR that God exists. Next, I argued that faith is not recalcitrant to evidence in the way that acceptance is. Additionally, since faith is not supposed to be actionguiding in only a small domain (e.g. only during mass), the acceptance in faith cannot be distinguished from belief on grounds of context. Finally, I argued that the belief-plus advocate has no reason to think that faith can be voluntarily formed in the same way that I can raise my arm, but that we might have a weak sort of voluntary control over beliefs, such that there are some praiseworthy or blameworthy beliefs. Since the acceptance in faith lacks the properties that distinguish acceptance from belief, there is no reason to think that McKaughan's trusting acceptance account of faith or Alston's account of faith implies the falsity of the belief-plus model.

\section{CONCLUSION}

McKaughan's hopeful affirmation account of faith fails to give sufficient conditions for faith. Following Howard-Snyder, I suggested that what is needed is some belief-like attitude toward the object of faith. McKaughan's trusting acceptance account offers just such a case. However, since the token acceptances in faith might be instances of belief, trusting acceptance being necessary and sufficient for faith does not imply the falsity of the belief-plus model. To be fair, McKaughan never claimed that it did. He argued that the belief-plus model is false because of the objection from doubt and meaning drift. However, I have argued that the objection from doubt either attacks a strawman or begs the question, and, assuming that McKaughan is right in thinking that word studies can illuminate the nature of faith, McKaughan's meaning drift objection actually bolsters the belief-plus model. I have argued that faith can meet the surprise condition that is necessary for belief, and that HowardSnyder's objection that one can have faith that $\mathrm{p}$ while believing that not-p begs the question against the belief-plus model. I conclude that McKaughan has given us no reason to deny that religious propositional faith implies belief. 


\section{BIBLIOGRAPHY}

Alston, W. 1996. 'Belief, acceptance, and religious faith', in Faith, Freedom, and Rationality (Lanham: Lowman \& Littlefield Publishers, Inc.), pp. 3-27, 241244

Alston, W. 2007. 'Audi on nondoxastic faith', in Rationality and the Good: Critical Essays on the Ethics and Epistemology of Robert Audi (Oxford: Oxford University Press), pp. 123-141

Audi, R. 1991. 'Faith, belief, and rationality', Philosophical Perspectives: 213-239

Bird, A. 1998. 'Dispositions and antidotes', The Philosophical Quarterly, 48 (191): 227-234

Cohen, L. J. 1992. An Essay On Belief and Acceptance (Oxford: Clarendon Press)

Dovidio, J. F., Gaertner, S. L., \& Kawakami, K. 2011. 'Racism', in Handbook of Prejudice, Stereotyping, and Discrimination (Thousand Oaks, CA: Sage), pp. 312-327

Frankish, K. 2004. Mind and Supermind (Cambridge: Cambridge University Press)

Heil, J. 2003. From An Ontological Point Of View (New York: Oxford University Press)

Howard-Snyder, D. 2013. 'Propositional faith: What it is and what it is not', American Philosophical Quarterly: 357-372

Jacobs, J. D. 2010. 'A powers theory of modality: Or, how I learned to stop worrying and reject possible worlds', Philosophical Studies, 151 (2): 227-248

Jordan, J. 2006. Pascal's Wager: Pragmatic Arguments and Belief that God Exists (Oxford: Oxford University Press)

Keren, G., \& Schul, Y. 2009. 'Two is not better than one: A critical evaluations of two-system theories', Perspectives on Psychological Science, 4 (6): 533-550

Lewis, D. 1973. Counterfactuals (Cambridge, MA: Harvard University Press)

Lewis, D. 1997. 'Finkish dispositions', Philosophical Quarterly, 47: 325-342

Martin, C. B. 2007. The Mind In Nature (Oxford: Oxford University Press)

Martin, C. B., \& Heil, J. 1998. 'Rules and Powers', Philosophical Perspectives, 12: 283-312

McKaughan, D. J. 2013. 'Authentic faith and acknowledged risk: Dissolving the problem of faith and reason', Religious Studies, 49 (1): 101-124

McKitrick, J. 2003. 'A case for extrinsic dispositions', Australasian Journal of Philosophy, 81 (2): 155-174

Mugg, J. 2013. 'Simultaneous contradictory belief and the two-system hypothesis', Proceedings of the 35th Annual Meeting of the Cognitive Science Society, pp. 1044-1048

Mumford, S. 1998. Dispositions (New York: Oxford University Press)

Pojman, L. 1986. 'Faith without belief?', Faith and Philosophy, 3 (2): 157-176 
Pruss, A. R. 2002. 'The actual and the possible', in Blackwell Guide to Metaphysics (Oxford: Blackwell), pp. 313-333

Sloman, S. A. 1996. 'The empirical case for two systems of reasoning', Psychological Bulletin, 119 (1): 3-32

Smith, W. C. 1998a. Believing: An Historical Perspective (Oxford: Oneworld Publications)

Smith, W. C. 1998b. Faith and Belief: The difference between them (Oxford: Oneworld Publications)

Stalnaker, R. 1984. Inquiry (Cambridge, MA: MIT Press)

Stanovich, K. 2011. Rationality and The Reflective Mind (Oxford: Oxford University Press)

Swinburne, R. 2005. Faith and Reason (Second edition) (Oxford: Oxford University Press)

Thompson, V. 2009. 'Dual process theories: A metacognitive perspective', in In Two Minds: Dual Processes and Beyond (Oxford: Oxford University Press), pp. 171-196)

Tversky, A., \& Kahneman, D. 1983. 'Extensional versus intuitive reasoning: The conjunction fallacy in probability judgment', Psychological Review, 90 (4): 293 